\title{
Inherited DNA amplification of the proximal 15q region: cytogenetic and molecular studies
}

\author{
C Mignon, F Parente, C Stavropoulou, P Collignon, A Moncla, C Turc-Carel, \\ M-G Mattei
}

\begin{abstract}
In a 15 year old girl, referred for growth retardation, conventional cytogenetic analysis detected an abnormal $15 q+$ chromosome with extra material in the proximal region, inherited from her father and grandfather. Using various molecular cytogenetic techniques, including comparative genomic hybridisation, we showed that the extra chromatin resulted from in situ amplification of DNA sequences located between the loci D15Z1 and D15S18. On the basis of the clinical features of our patient and the late replication of the large amplified region, we searched for functional modifications in the adjacent Prader-Willi syndrome region. (F Med Genet 1997;34:217-222)
\end{abstract}

Keywords: inherited DNA amplification; proximal 15q; in situ hybridisation; methylation.

The proximal $15 q 11-q 12$ region appears to be prone to various types of rearrangements including deletions, translocations, duplications, triplications, and inv dup(15) supernumerary chromosomes. Deletions, and less frequently translocations, have been reported in association with Prader-Willi syndrome (PWS) and Angelman syndrome (AS). ${ }^{1}$ Inv dup(15) extra chromosomes are associated with both normal and abnormal phenotypes including dysmorphism, mental retardation, and severe epilepsy. ${ }^{2-6}$ Finally, the few reported cases of intrachromosomal duplications and triplications of the same region are associated with a normal phenotype, PWS or AS, or a phenotype very similar to that found in inv $\operatorname{dup}(15)$ patients. $^{7-9}$

We report here a 15 year old girl referred for cytogenetic analysis because of short stature. Her karyotype showed an abnormal chromosome 15 with extra chromatin in the proximal long arm. Fluorescence in situ hybridisation (FISH) techniques, including comparative genomic hybridisation (CGH), further defined an amplification of DNA sequences located between the centromere of chromosome 15 and the D15S18 locus. This extra chromatin appeared as a large late replicated segment, adjacent to the PWS region. That the patient shared some clinical signs with PWS raised the possibility that the amplification modifies the expression of genes in the Prader-Willi syndrome region by a mechanism similar to position effect variegation (PEV) seen in Drosophila. ${ }^{11}{ }^{11}$ Indications of functional modi- fication in the PWS region were sought by two methods, DNA replication analysis using FISH and methylation study.

Replication timing and genetic activity have been correlated in various situations, and tissue specific genes generally replicate earlier when they are expressed than when they are not. ${ }^{12-14}$ Moreover, asynchronous replication has been reported for imprinted genes that display allele specific expression. ${ }^{15} 16$ We therefore searched for a modification in the replication timing of the imprinted SNRPN gene (small nuclear ribonucleoprotein polypeptide $N$ ) in our patient. SNRPN maps to the PWS region.

The PWS region has been characterised by specific DNA methylation imprinting at several loci. ${ }^{17-20}$ We therefore analysed a possible modification of the methylation status at one of these loci, D15S63, in our patient. We conclude that the extra chromatin in our patient can be likened to a homogeneously staining region, without phenotypic effect.

\section{Case report}

The proband, a white female, was the product of an uneventful term pregnancy and a normal delivery. Birth weight was $3330 \mathrm{~g}$ and length 48 $\mathrm{cm}$. The postnatal course was normal; however, slight hypotonia was noticed from birth to 3 months of age, without sucking difficulties. The proband was referred at the age of 15 years for short stature (height $139 \mathrm{~cm},-3$ SD). At the time of the consultation, her weight was $38 \mathrm{~kg}$ and she had a tendency to hyperphagia. She did not show any dysmorphic features, mental retardation, or hypotonia and had a normal puberty. She had had eczema and asthma from 2 years of age. Her family history was unremarkable and her parents were healthy. The height of her mother and father were 160 and $159 \mathrm{~cm}$, respectively. The height of her paternal grandmother was $160 \mathrm{~cm}$ and that of her paternal grandfather $154 \mathrm{~cm}$.

\section{Materials and methods}

CONVENTIONAL AND MOLECULAR CYTOGENETICS Cytogenetic analyses of the patient and all family members were performed on cultures from peripheral lymphocytes using standard techniques. Preparations were RHG and CBG stained. 5-BrdU was incorporated (final concentration $60 \mu \mathrm{g} / \mathrm{ml}$ of medium) during the last seven hours of culture in order to identify the late replicated chromosome regions (RBG).

Probes with small insert size, pIR39 (D15S18), pTD3.21 (D15S10), and pTD189.1 (D15S13), were purchased from 
A

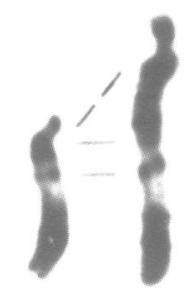

RHG
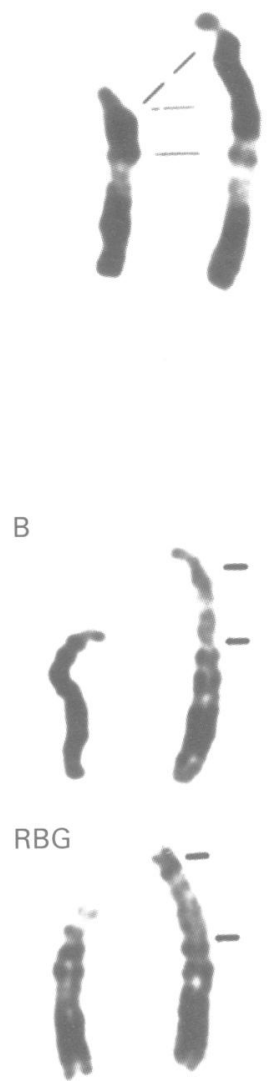

Figure 1 Partial karyotypes of chromosomes 15 from the proband (chromosome $15 q+$ is on the right). (A) Extra chromatin appears as a large positive $R$ band after $R H G$ banding. (B) Extra material appears late replicating after $B r d U$ incorporation and $R B G$ banding.

American Type Culture Collection (ATCC). They were tritium labelled by nick translation and hybridised as previously described. ${ }^{21}$ After coating with nuclear track emulsion (Kodak NTB2) the slides were exposed for 15 days at $4^{\circ} \mathrm{C}$, then developed. $\mathrm{R}$ banding was performed by the fluorochrome-photolysis-giemsa method. One hundred metaphases were analysed for each probe. The percentage of silver grains on the $15 \mathrm{q}+$ chromosome was compared to that observed on the normal chromosome 15 , to determine the locus copy number.

When cosmids were available, fluorescence in situ hybridisation (FISH) was performed as recommended by the supplier (ONCOR Inc, Gaithersburg). Biotinylated cosmids corresponding to D15S11 and GABRB3 loci were detected by FITC conjugated avidin (Biosys Vector Laboratories cat A2011), as described by Pinkel et al. ${ }^{22}$ Digoxigenin labelled cosmid corresponding to SNRPN was detected by a mouse monoclonal antidigoxigenin antibody (Boehringer Mannheim cat 1333.062) and fluorescein conjugated antimouse antibody (Boehringer Mannheim cat 1214.616). Two other probes were hybridised on metaphases of the proband: the biotinylated alpha satellite DNA probe D15Z1 and the specific chromosome 15 library (from ONCOR).

COMPARATIVE GENOMIC HYBRIDISATION (CGH) CGH was performed according to the protocol of Du Manoir et al. ${ }^{23}$ Briefly, test DNA and reference DNA were differentially labelled with biotin-14-dATP and digoxigenin-11-dUTP (Boehringer Mannheim cat 1558.706) respectively, using commercially available nick translation systems (Gibco, Life Technologies). A total of 200-400 ng of both DNAs was coprecipitated in the presence of $20 \mu \mathrm{g}$ cotI DNA (Gibco, BRL), dissolved in hybridisation mixture, denatured at $70^{\circ} \mathrm{C}$ for 10 minutes, and preannealed at $37^{\circ} \mathrm{C}$ for one hour. Hybridisation was carried out on reference metaphase spreads for two to three days, at $37^{\circ} \mathrm{C}$, in a moist chamber. Posthybridisation washes were done according to the regular FISH protocol described by Pinkel et al. ${ }^{22}$ For the detection of biotin molecules, we used FITC conjugated avidin (Biosys Vector Laboratories cat A2011). Digoxigenin labelled DNA was visualised after incubations with monoclonal antibody to digoxigenin from mousemouse hybrid cells (Boehringer Mannheim cat 1333.062), antimouse Ig-digoxigenin $F\left(a^{\prime}\right) 2$ fragment (Boehringer Mannheim cat 1214.624), and antidigoxigenin-rhodamine Fab fragment (Boehringer Mannheim cat 1207.750). Images of the hybridised metaphases were evaluated with a digital image analysis system (Alcatel Answare TITN, France) based on a Zeiss fluorescence microscope and a cooled CCD camera (Hamamatsu).

DNA REPLICATION ANALYSIS BY FISH

FISH to interphase nuclei is a sensitive method for assaying replication of genomic sites. ${ }^{24}$ Hybridised sequences appear as two single signals in cells that have not replicated (G1), as two pairs of doublets in cells in which both homologues have replicated (G2), and as a singlet and a doublet in cells where only one homologue has replicated (G1-G2 cells).

Interphase nuclei from our patient and two normal subjects were obtained from PHA stimulated lymphocytes without synchronisation, as described by Selig et al. ${ }^{24}$ Nuclei preparations were treated with Proteinase K (100 $\mathrm{ng} / \mathrm{ml}$ in Tris- $\mathrm{HCl} 20 \mathrm{mmol} / \mathrm{l}, \mathrm{CaCl}_{2} 2 \mathrm{mmol} / \mathrm{l}$, $\mathrm{pH}$ 7.4) before hybridisation, and FISH with the digoxigenin labelled SNRPN cosmid was performed as recommended by the supplier (ONCOR, Gaithersburg). The hybridised signals were detected as described above. Over 200 nuclei were observed for each subject.

\section{METHYLATION STUDIES}

The methylation status was studied with the pW71 probe located at the D15S63 locus. ${ }^{17}$ DNA was extracted from the patient, her parents, and paternal grandparents by standard methods. DNA was digested with two restric- 


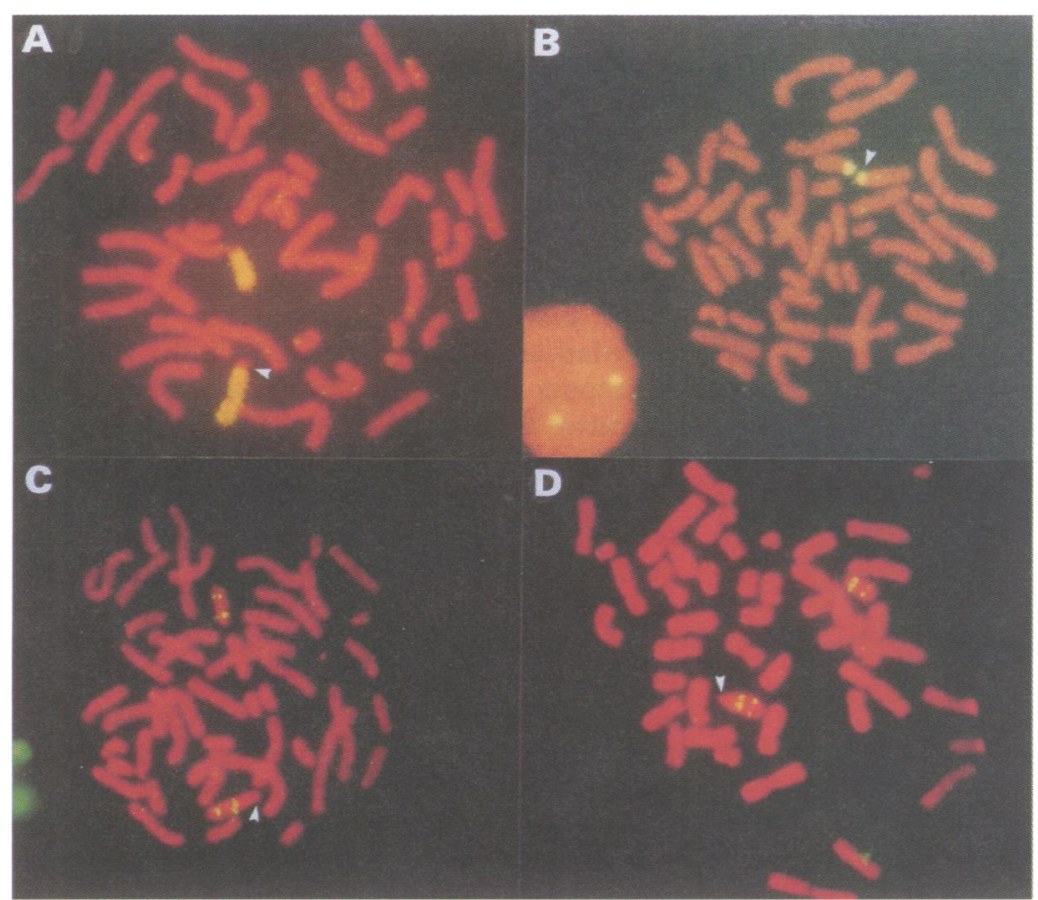

Figure 2 Fluorescence in situ hybridisation with several biotinylated probes on metaphases of the proband (arrowheads indicate the chromosome 15q+). (A) Specific chromosome 15 library shows homogeneous painting on the whole abnormal chromosome 15. (B) D15Z1 probe detected normal signals on both normal and abnormal chromosomes 15. (C) D15S11 cosmid gives an identical signal on both chromosomes 15, but it appears shifted towards the middle on the 15q+. Cohybridised Myl cosmid gives a subdistal signal indicating the chromosomes 15. (D) Similar results are obtained with GABRB3 cosmid.

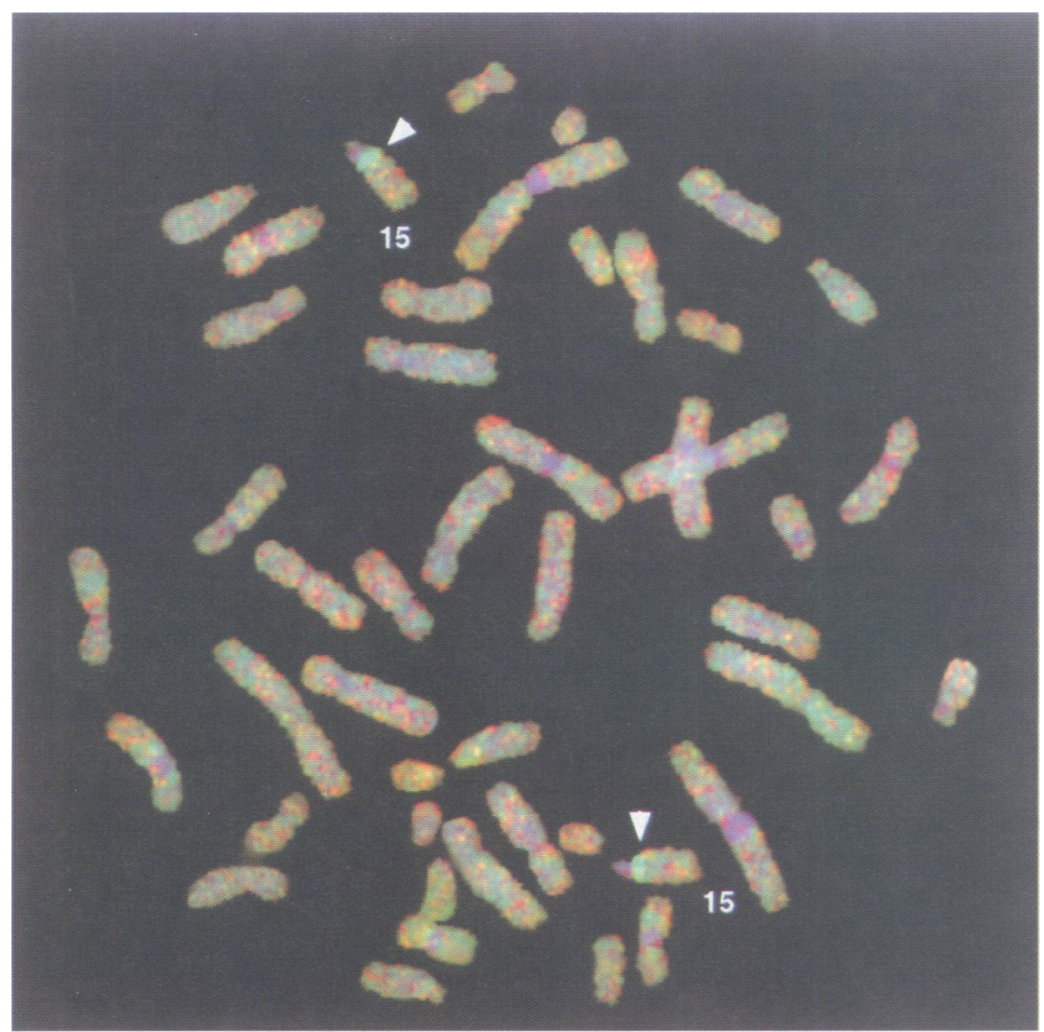

Figure 3 Comparative genomic hybridisation with proband's DNA on metaphase of a normal subject. Arrowheads show the amplified DNA in the juxtacentromeric long arm of both chromosomes 15.
Hybridisation was performed at $65^{\circ} \mathrm{C}$ for 18 to 24 hours in a roller bottle hybridisation oven with $6 \times$ SSC, $0.5 \%$ SDS, $2.5 \times$ Denhardt's solution, $5 \%$ dextran sulphate, and herring sperm DNA $(100 \mu \mathrm{g} / \mathrm{ml})$. The filter was then washed at $65^{\circ} \mathrm{C}$ to a final stringency of $2 \times$ SSC $/ 0.1 \%$ SDS and exposed to $x$ ray film.

When probe $\mathrm{pW} 71$ was hybridised with normal DNA, two bands were observed: one of 6.0 $\mathrm{kb}$ corresponding to the methylated allele (maternal), the other of $4.4 \mathrm{~kb}$, corresponding to the non-methylated allele (paternal).

\section{Results}

CONVENTIONAL AND MOLECULAR CYTOGENETICS Conventional cytogenetics performed in our patient identified an elongated chromosome 15 , with positive $R$ banded extra material in the proximal long arm (fig 1A). The extra material was not stained by the CBG technique (data not shown) but was shown to be late replicating by BrdU incorporation (fig 1B). Karyotypes of the proband's parents and paternal grandparents show that the abnormal chromosome 15 is present in both the father and the paternal grandfather.

FISH analysis with a chromosome 15 specific library probe showed homogeneous painting of the whole abnormal chromosome 15 , excluding an insertion of material from elsewhere in the genome (fig 2A). FISH with biotinylated centromeric $\mathrm{D} 15 \mathrm{Z} 1$ probe detected normal signals on both normal and abnormal chromosomes 15 (fig 2B).

Several cases of elongated chromosome 15 have been shown to result from duplication or triplication of the $15 \mathrm{q} 11-\mathrm{q} 12$ region involved in PWS and AS. To test whether a duplication of this region underlies the abnormal karyotype described in this study, in situ hybridisation was performed with various probes from the 15q11-q12 region; cosmids for D15S11, GABRB3, and SNRPN loci each showed only one signal on the elongated chromosome 15 (fig $2 \mathrm{C}, \mathrm{D}$ ), excluding a duplication or a triplication of these loci. Isotopic in situ hybridisation was performed with pIR39 (D15S18), pTD3.21 (D15S10), and pTD189.1 (D15S13) probes. From the 100 metaphases analysed with each probe, there was no difference in the hybridisation signal between the two chromosomes 15 and no silver grains were detectable in the extra material of the abnormal 15. Moreover, all the probes from the PWS/AS region gave a hybridisation signal shifted towards the middle of chromosome $15 \mathrm{q}+$, confirming that the extra material is located proximal to this region.

COMPARATIVE GENOMIC HYBRIDISATION

As the abnormal chromosome $15 \mathrm{q}+$ did not seem to result from an increase in the copy number of the PWS/AS region, we tried to define the origin of the extra material by comparative genomic hybridisation. CGH was performed using total DNA from the proband as a probe and gave a clear signal in the juxtacentromeric long arm of the chromosome 15 pair in a normal subject (fig 3 ). This result was in gel electrophoresis, and transferred to nylon membrane (PALL) by the method of Southern. ${ }^{25}$ DNA probe was labelled with $\alpha-{ }^{32} \mathrm{P}$ dCTP by the random primer method. ${ }^{26}$ 
Figure 4 Methylation studies with $p W 71$ probe hybridised on HindIII/HpaII digested $D N A$ from GF: grandfather, GM: grandmother, $F$ : father, M: mother, and P: proband. There is no significant difference in intensity between the methylated band of $6.0 \mathrm{~kb}$ and the unmethylated band of $4.4 \mathrm{~kb}$ in the proband.

agreement with in situ amplification of a very proximal DNA sequence, located between D15Z1 and D15S18 loci, in our patient.

DNA REPLICATION ANALYSIS BY FISH

The amplification observed in the $15 \mathrm{q}+$ chromosome gives rise to a late replicated homogeneous staining region (HSR), adjacent to a PWS region of paternal origin. As the SNRPN gene may be involved in the PWS, ${ }^{19}$ we investigated a possible decrease in its activity by studying the replication timing at this locus. Such a decrease would be expected to correlate with a delay in the replication timing of the expressed paternal allele, resulting in a reduced replication asynchronism. After in situ hybridisation with the SNRPN cosmid, 200 nuclei were scored from our patient and each normal subject. Nuclei with one single and one double signal were in a range of $30-34 \%$, showing no significant difference between the three subjects, and values similar to those described by Kitsberg et $a l^{15}$ and Knoll et al. ${ }^{16}$ Nuclei with two single signals were between 57 and $62 \%$ and nuclei with two pairs of signals were in the range of 7 and $12 \%$. We conclude that the late replication of the extra chromatin has no effect on the replication timing of the nearby SNRPN locus.

\section{METHYLATION STUDIES}

In order to investigate further the possibility of functional modification in the adjacent PWS region, we studied the methylation status at the D15S63 locus. Analyses of DNA from our patient, her parents, and paternal grandparents were carried out using the pW71 probe. The results showed two bands in all tested subjects a maternal methylated band of $6.0 \mathrm{~kb}$ and a paternal unmethylated band of $4.4 \mathrm{~kb}$ (fig 4). There was no difference in intensity of the two bands in the proband and her parents, in agreement with a normal methylation pattern of the D15S63 locus. On the other hand, in both grandparents of our patient, we observed a slightly decreased intensity of the methylated band which could be explained by a general demethylation of the genome with increased age. ${ }^{27}$ We conclude that the late replicated extra chromatin does not modify the methylation status at the D15S63 locus, and probably does not affect the activity of the paternal alleles in the PWS region.

\section{Discussion}

A 15 year old girl was referred for growth retardation that, associated with neonatal hypotonia and a tendency to hyperphagia, was evocative of some aspects of PWS. Cytogenetic analysis detected an abnormal $15 q+$ chromosome with extra material in the proximal region. Family study indicated that the elongated chromosome was inherited through the father and the paternal grandfather of the proband, who also had short stature. This observation raised two important issues: firstly, whether there was a correlation between the presence of the extra material and the phenotype of the proband, and, secondly, as the region involved is imprinted, whether there was any risk of this $15 q+$ being associated with a more severe phenotype in cases of maternal transmission.

Several cases of elongated chromosomes 15 have been published and interpreted as an insertional duplication or triplication from the proximal $15 \mathrm{q}$ region. However, no consistent phenotype has been associated with such a chromosomal abnormality; some $15 \mathrm{q}$ duplications appear to be phenotypically silent, ${ }^{28-32}$ others associated with atypical PWS ${ }^{29}{ }^{33-36}$ or $\mathrm{AS},{ }^{37}{ }^{38}$ and others with unexplained mental retardation $^{32} 3940$ or repeated miscarriages. ${ }^{30} 32$ Rare cases of triplication are associated with motor and mental retardation. ${ }^{89}$ It has to be noted that very few cases of so called "duplications" or "triplications" of the proximal 15q region have been analysed with molecular techniques and phenotypic discordances probably result from differences in the content of the extra chromatin. Using FISH techniques in our patient, we identified the extra material as resulting from in situ amplification of a DNA sequence lying between the D15Z1 and D15S18 loci, located proximal to the PWS/AS region. Some cases of supernumerary inv dup(15) chromosomes, containing a slight expansion in this region, are associated with a normal phenotype, ${ }^{441}$ suggesting the possibility that non-transcribed sequences are involved. Thus, we conclude that the abnormal $15 \mathrm{q}+$ chromosome is probably not directly related to the phenotype observed in our patient.

Nevertheless, the late replication of the extra material, its location near an imprinted region, and also its large size, led us to search for a kind of "position effect" on adjacent regions. Such an effect has been observed in Drosophila, where euchromatic genes exhibit a decrease in expression when they are placed next to heterochromatin by chromosomal rearrangement. ${ }^{10} 11 \mathrm{~A}$ similar phenomenon has been observed when mammalian autosomal genes are fused to the inactive $\mathrm{X}$ chromosome. We investigated a possible decreased expression of genes located in the adjacent PWS 
region by two methods: replication timing analysis by FISH and methylation study.

Using FISH to interphase nuclei, we found no difference in the level of asynchronous replication of the imprinted SNRPN gene in our patient compared to normal subjects. Kawame et $a l^{42}$ hypothesised that the apparent replication asynchrony by FISH analysis of imprinted loci reflects structural differences between the maternal and the paternal alleles, rather than differences in replication timing. Nevertheless, in such a situation, our results would indicate that the extra chromatin in our patient did not modify the chromatin structure at the SNRPN locus.

Secondly, we analysed the methylation status of the imprinted D15S63 locus, ${ }^{17}$ which maps $130 \mathrm{~kb}$ centromeric to SNRPN. The methylation pattern was normal in the patient and her parents, allowing us to conclude that the extra late replicated chromatin had no effect on the adjacent PWS region. In both grandparents (83 and 86 years old), a slight decrease of the methylated band was observed, possibly resulting from a general demethylation of the genome with increased ageing. ${ }^{27}$

Finally, we conclude that the extra chromatin observed in our patient has no phenotypic effect in carriers. It could be compared to "homogeneously staining regions" (HSRs) that are frequently observed in the genome of tumour cells ${ }^{43}$ and drug resistant cell lines, ${ }^{44}$ but are generally not found in normal tissues. ${ }^{45}$ A similar HSR, transmitted through the germline and associated with a normal phenotype, has however been described in Mus musculus domesticus. ${ }^{46}{ }^{47}$

In summary, our study highlights the necessity of determining precisely the nature of any extra chromatin in the proximal $15 \mathrm{q}$ region. Rare observations studied with molecular techniques $^{8938}$ (this observation) confirm the results obtained from small supernumerary inv dup(15) chromosomes. Any increased dosage of genes in the PWS/AS critical region causes an abnormal phenotype, dependent on the copy number and the parental origin. Nevertheless, increased copy number of sequences from the region proximal to the PWS/AS critical region seems to be associated with a normal phenotype.

This work was supported by FNLCC (Féderation Nationale des Centres de Lutte Contre le Cancer), ARC (Association pour Recherche sur le Cancer), FRM (Fondation pour la Recherch Médicale), CNRS (Centre National de Recherche Scientifique), and the Fondation de France. We wish to thank $D$ Depetris, $\mathbf{N}$ Roeckel, and J Ambert for efficient technical assistance and $M$ Mitchell for critical reviewing of the manuscript.

1 Ledbetter DH, Cassidy SB. Etiology of Prader-Will syndrome. In:Caldwell ML, Taylor RL, eds. Prader-Wilh syndrome: selected research and management issues. New York: Springer, 1988:13-28.

2 Robinson WP, Binkert F, Giné R, et al. Clinical and molecular analysis of five inv dup (15) patients. Eur f Hum Genet 1993;1:37-50

3 Leana-Cox J, Jenkins L, Palmer CG, et al. Molecular cytogenetic analysis of inv dup (15) chromosomes, using probes specific for the Prader-Willi/Angelman syndrome region: clinical implications. Am $f$ Hum Genet 1994;54 748-56. somes. $\mathcal{f}$ Med Genet 1994;31:585-94.

NR Supernumerary marker 15 chromosomes: a clinical, molecular and FISH approach to diagnosis and prognosis. Hum Genet 1995;95: $161-70$.
6 Mignon C, Malzac P, Moncla A, et al. Clinical heterogeneity in 16 patients with inv dup 15 chromosomes: cytogenetic and molecular studies, search for an imprinting effect. Eur 7 Hum Genet 1996;4:88-100.

7 Ludowese CJ, Thompson KJ, Sekhon GS, Pauli RM. Absence of predictable phenotypic expression in proximal 15q duplications. Clin Genet 1991;40:194-201.

8 Holowinsky S, Black SH, Howard-Peebles PN, et al. Triplication 15q11-13 in two unrelated patients with hypotonia, cognitive delays and visual impairment. Am $\mathcal{f} \mathrm{Hum}$ Genet 993;53:A125.

9 Schinzel AA, Brecevic L, Bernasconi F, et al. Intrachromosomal triplication of 15q11-q13. F Med Genet 1994;31:798803.

10 Heitz E. Die somatische Heteropyknose bei Drosophila melanogaster und ihre genetische Bedeutung. $Z$ Zellforsch 1933;20:237-87.

11 Eissenberg JC. Position effect variegation in Drosophila: towards a genetics of chromatin assembly. BioEssays 1989; 11:14-17.

12 Goldman MA, Holmquist GP, Gray MC, Caston LA, Nag A. Replication timing of mammalian genes and middle repetitive sequences. Science 1984;224:686-92.

13 Holmquist GP. Role of replication time in the control of tissue-specific gene expression. Am $\mathcal{f}$ Hum Genet 1987;40: 151-73

14 Hatton KA, Dhar V, Brown EH, et al. Replication program of active and inactive multigene families in mammalian cells. Mol Cell Biol 1988;8:2149-58.

15 Kitsberg D, Selig S, Brandeis M, et al. Allele-specific replication timing of imprinted gene regions. Nature 1993; 364:459-3.

16 Knoll JHM, Cheng SD, Lalande M. Allele specificity of DNA replication timing in the Angelman/Prader-Willi syndrome imprinted chromosomal region. Nat Genet 1994;6: $41-6$

17 Dittrich B, Robinson WP, Knoblauch H, et al. Molecular diagnosis of the Prader-Willi and Angelman syndromes by detection of parent-of-origin specific DNA methylation in 15q11-q13. Hum Genet 1992;90:313-15.

18 Driscoll DJ, Waters MF, Williams CA, et al. A DNA methylation imprint, determined by the sex of the parent, distinguishes the Angelman and Prader-Willi syndromes. Genomics 1992;13:917-24.

19 Özçelik T, Leff S, Robinson W, et al. Small nuclear ribonucleoprotein polypeptide N (SNRPN), an expressed gene in the Prader-Willi syndrome critical region. Nat Genet 1992; 2:265-9.

20 Buiting K, Saitoh S, Gross S, et al. Inherited microdeletions in the Angelman and Prader-Willi syndromes define an imprinting centre on human chromosome 15. Nat Genet 1995;9:395-400.

21 Mattei MG, Philip N, Passage E, Moisan JP, Mandel JL, Mattei JF. DNA probe localization at $18 \mathrm{p} 113$ band by in situ hybridization and identification of a small supernumerary chromosome. Hum Genet 1985;69:268-71.

22 Pinkel D, Straume T, Gray JW. Cytogenetic analysis using quantitative, high sensitivity fluorescence in situ hybridization. Proc Natl Acad Sci USA 1986;83:2934-8.

23 Du Manoir S, Speicher MR, Joos S, et al. Detection of complete and partial chromosome gains and losses by plete and partial chromosome gains and losses by 590-610.

24 Selig S, Okumura K, Ward DC, Cedar H. Delineation of DNA replication time zones by fluorescence in situ hybridization. $E M B O$ f 1992;11:1217-25.

25 Southern EM. Detection of specific sequences among DNA fragments separated by gel electrophoresis. I Mol Biol 1975;98:503-17.

26 Feinberg AP, Vogelstein B. A technique for radiolabelling DNA restriction fragments to high specific activity. Anal Biochem 1983;132:6-13.

27 Wareham KA, Lyon MF, Glenister PH, Williams ED. Age related reactivation of an X-linked gene. Nature 1987;327 725-7.

28 Stallard R, Van Dyke D. Familial duplications of proximal $15 \mathrm{q}$ in normal individuals. Am $\mathcal{F}$ Hum Genet 1986;39:A133.

29 Berry R, McGavran L, Robinson J, Staley L. Familial duplication of proximal 15q in Prader-Willi individual and her normal father. Am f Hum Genet 1987;41:A114.

30 Brookwell A, Veleba A. Proximal 15q variant with norma phenotype in three unrelated individuals. Clin Genet 1987 31:311-14

31 Shohat M, Shohat T, Rimoin DL, et al. Rearrangement of chromosome 15 in the region q11.2-q12 in an individual with obesity syndrome and her normal mother. $A m \mathcal{F} M e d$ Genet 1990;37:173-7.

32 Wenger GD, Labanowska JM, Moore JW. Cytogenetic and molecular cytogenetic (FISH) analysis of the duplication of band 15q12. Am F Hum Genet 1993;53:A623.

33 De France HF, Beemer FA, Ippel PF. Duplication in chromosome $15 \mathrm{q}$ in a boy with Prader-Willi syndrome; further cytogenetic confusion. Clin Genet 1984;26:379-82.

34 Furhman-Rieger A, Köhler A, Furhman W. Duplication or insertion in 15q11-13 associated with mental retardationshort stature and obesity-Prader-Willi or Cohen syndrome. Clin Genet $1984 \cdot 25 \cdot 347-52$.

35 Pettigrew AL, Gollin SM, Greenberg F, Riccardi VM, Ledbetter DH. Duplication of proximal $15 \mathrm{q}$ as a cause of Prader-Willi syndrome. Am F Med Genet 1987;28.791-802. 36 Rauch LA, Nevin NC. Duplication of $15 \mathrm{q} 11.2-15 \mathrm{q} 13$ in five cases with different phenotypes. $\mathcal{f}$ Med Genet 1991;28 
37 Mutirangura A, Kuwano A, Robinson WP, Greenberg F Malcolm S, Ledbetter DH. Duplication of chromosom $15 \mathrm{q}$ in Prader-Willi and Angelman syndromes : a gene dosage paradox. Am f Hum Genet 1993;53:A584.

38 Clayton-Smith J, Webb T, Cheng XJ, Pembrey ME Malcolm S. Duplication of chromosome 15 in the regio 15q11-13 in a patient with developmental delay and ataxia with similarities to Angelman syndrome. F Med Genet 1993;30:529-31

39 Turolla L, Baccichetti C, Artifoni L, Lenzini E, Leszl A Tenconi R. A new family with extra material on proximal 15q. Ann Genet (Paris) 1989;32:230-2.

40 Veenema H, Beverstock GC, Zvelebil-Tarasevitch N, Doorn JL, Van Parys JAP, Kamp JJP. Duplication in the proximal portion of the long arm of chromosome 15 , in a girl withportion of the long arm of chromosome 15 , in a girl withGenet 1984;26:65-8.

41 Cheng SD, Spinner NB, Zackai EH, Knoll JHM. Cytogenetic and molecular characterization on inverted duplcated chromosomes 15 from 11 patients. Am f Hum Genet 1994;55:753-9.
42 Kawame H, Gartler SM, Hansen RS. Allele-specific replication timing in imprinted domains: absence of asynchrony at several loci. Hum Mol Genet 1995;4:2287-93.

43 Gerbault-Seureau M,Vielh P, Dutrillaux B. Recurrent HSR in the centromeric region of chromosome 8 in breast cancer. Ann Genet (Paris) 1987;30:146-51.

44 Cowell JF. Double minutes and homogeneously staining regions: gene amplification in mammalian cells. Annu Rev Genet 1982;16:21-59.

45 Wright JA, Smith HS, Watt FM, Hancock MC, Hudson DL, Stark GR. DNA amplification is rare in normal human cells. Proc Natl Acad Sci USA 1990;87:1791-5.

46 Traut $\mathrm{W}$, Winking $\mathrm{H}$, Adolph $\mathrm{S}$. An extra segment in chromosome 1 of wild Mus musculus: a C-band positive homogeneously staining region. Cytogenet Cell Genet 1984;38: 290-7.

47 Boldyreff B, Winking H, Weith A, Traut W. Evidence for in situ amplification of a germ line homogeneously staining region in the mouse. Cytogenet Cell Genet 1988;47:84-5. 